\title{
Os passos para a construção de sentido pela criança e seu interlocutor no cenário enunciativo
}

\author{
Suzana Rosa de Almeida \\ Universidade Federal de São Paulo (UNIFESP), São Paulo, São Paulo, Brasil \\ suzi.almeid@hotmail.com \\ Juliana Perez Kiihl \\ Universidade Federal de São Paulo (UNIFESP), São Paulo, São Paulo, Brasil \\ julianakiihl@hotmail.com
}

DOI: http://dx.doi.org/10.21165/el.v46i2.1573

\begin{abstract}
Resumo
A construção de sentido da palavra não se esgota em uma referência fixa e unissignificativa (LURIA, 1986). A Teoria das Operações Enunciativas comunga essa ideia, acreditando não existir sentidos prévios à materialidade verbal (CULIOLI, 1990; DE VOGUÉ; FRANCKEL; PAILLARD, 2011). O objetivo principal deste artigo é analisar os recursos linguísticos e contextuais utilizados pela criança para estabilizar o sentido de uma palavra. Como corpus, analisaremos o cenário enunciativo de duas crianças, dados pertencentes ao Banco de dados NALíngua (CNPq/UNESP-FCLAr), coordenado por Del Ré. A análise centra-se nas interações lúdicas envolvendo questionamentos, de um lado, da criança em busca da construção de um sentido e, de outro, de seu interlocutor sobre o que ela traz como sentido. Como resultado, mostramos a existência de um jogo contextual, no qual a criança constrói um sentido relacional de palavras, e sinaliza seus primeiros passos criativos no movimento de ajustamento linguístico.

Palavras-chave: Teoria das Operações Enunciativas; processo de construção de sentido; aquisição de linguagem.
\end{abstract}

\section{The steps of meaning construction by children and their interlocutors in an enunciative scenary}

\begin{abstract}
The action of building the meaning of a word is not finished in a settled reference with only one meaning, (LURIA, 1986). The Theory of Enunciative Operations agrees with this idea, claiming the non-existence of previous meanings before the act of enunciating. (CULIOLI, 1990; DE VOGÜÉ; FRANCKEL; PAILLARD, 2011). The main goal of this article is to analyze the language and contextual resources used by children to stabilize the meaning of a word. As research corpus, we will analyze the enunciative scenario of two children, in which the data belong to the Banco de dados NALíngua [NALingua Database] (CNPq/UNESP-FCLar), coordinated by Del Ré. On one hand, the analysis focuses on the playful interactions involving children's questioning order to build the meaning, and, on the other hand, on the interlocutor's questions on how children brought up meaning during the interactions. The analysis focuses on the playful interactions involving children's questionings in order to build the meaning and an interlocutor leading the children to comprehend the meaning they brought up during the interaction situations. As a result we intend to show the existence of a contextual game in which the children, in general, build the meanings of the words and indicate their first creative steps in the adjustable movement of language itself.
\end{abstract}

Keywords: Theory of Enunciative Operations; process of meaning building language acquisition. 


\section{Introdução}

Descobrir novos lados de uma palavra era o mesmo que descobrir novos lados do ser. Manoel de Barros

Pensar na atividade de linguagem da criança nos convida a refletir sobre esse fenômeno de maneira interdisciplinar. Nessa perspectiva, buscamos a construção de diálogos entre diferentes esferas do conhecimento e concordamos que talvez os poetas e as crianças tenham muito a nos ensinar sobre a linguagem, pois são os que melhor sabem brincar com ela e dela usufruir (YAGUELLO, 1991).

O complexo processo de aquisição de linguagem pela criança, que prevê interação, afeto, troca, desenvolvimento cognitivo e psíquico, traz à tona a necessidade de analisar fenômenos linguísticos e intelectuais a partir de diferentes vieses, impossibilitando uma análise sob a ótica de uma única e exclusiva área de conhecimento.

Diferentes estudos são colocados em jogo quando abordamos a aquisição de linguagem, como, por exemplo, os advindos da área da educação, da linguística, da psicologia e da neurociência. Para isso, há uma exigência de nos fundamentarmos em teorias que compreendam o desenvolvimento de processos de forma ampla, que tenham em seu âmago a visão da complementaridade das diferentes áreas e busquem com elas dialogar.

Nesta investida, recorremos a dois autores que, a nosso ver, partilham da visão de ampliar os olhares para outros campos: Luria, que se volta para a neurologia, a psicologia e a linguística, e Culioli, que explora a área da psicologia, da cognição, entre outras, a fim de possibilitar um maior entendimento e aprofundamento a respeito de um processo que envolve a linguagem, o cognitivo e o social.

Luria, pesquisador e colaborador de Vigotski, manteve a característica de pesquisa de seu mentor sobre a linguagem e o pensamento, ao considerar o caráter mediado da atividade psíquica e da origem dos processos psíquicos interiores na atividade externa e interpsíquica dos sujeitos. Isto significa considerar a linguagem e o pensamento como atividades de fundo social, nas quais o homem se forma e interage com seus semelhantes em uma relação baseada na troca (BEZERRA, 2010).

O conceito de mediação, presente em Vigotski e também em Luria, aparece como imprescindível na relação entre homem e mundo, já que a troca só é realizada através do discurso, da formação de ideias, pensamentos que o homem possui sobre seu meio e utiliza para nele atuar, sendo necessário entender o signo como instrumento de mediação para tal (BEZERRA, 2010).

É fácil concordar com os autores sobre a necessidade da interação e do social no processo de aquisição de linguagem, e isso por ser evidente que é no contato com o outro, na troca, que as palavras são aprendidas e os sentidos são, por sua vez, construídos e apreendidos. Na intenção de ilustrar esse diálogo entre teorias, trazemos dois exemplos que demonstram os ajustes e a reflexão necessária, nas duas partes envolvidas, para que os sujeitos se façam entendidos e compreendam o outro. Isso porque, é na interação que nos deparamos com certas necessidades para as quais usamos atividades específicas, refletindo as condições do mundo externo no organismo, e, 
elaborando informações (LURIA, 1986), experimentamos e adequamos as palavras e o raciocínio em um eterno jogo cognitivo e linguístico.

Corroborando essa visão, trazemos a Teoria das Operações Enunciativas (TOE), referencial no qual nos fundamentamos ao abordar conceitos como o de elaboração de sentido, identidade semântica da palavra e processos de representação, referenciação e regulação - processos esses constitutivos da atividade de enunciação. Com a mesma importância de Luria e Vigotski, os quais revolucionaram o modo de se fazer pesquisa na área da psicologia, Antoine Culioli também trouxe para sua época e contexto de pesquisa em semântica uma abordagem distinta, que postula um modo diferenciado de analisarmos a unidade linguística, seus sentidos e a maneira como a significação se elabora nos enunciados.

Portanto, a atividade de linguagem é o principal objeto de sua teoria, que, assim como Vigotski, entende o pensamento e a linguagem como "questão fulcral de toda a psicologia do homem e leva diretamente o pesquisador a uma nova teoria psicológica da consciência" (VIGOTSKI, 2010, p. XIX), visto Culioli propor uma nova possibilidade para o que se entende como cognição e para o modo como se dá sua relação com a produção linguística.

Neste trabalho, buscamos apresentar as contribuições dos referidos autores sobre o processo de construção de sentido na fala infantil, cujos cenários enunciativos são marcados pelos passos da criança na linguagem, os quais incluem o brincar com as palavras e a criação de imagens a partir de uma língua entendida intrinsecamente como dinâmica, o que nos auxilia a refletir sobre o próprio funcionamento da atividade de linguagem humana.

Conforme mencionado, ao trazer dois exemplos de situações reais de interação com crianças, temos o objetivo de analisar os recursos linguísticos e contextuais mobilizados por elas para estabilizar o sentido de palavras e expressões, estabilização necessariamente vinculada aos movimentos de ajustamento presentes em toda forma de interação e diálogo. Consideramos que é possível, com essa análise, observar que toda vivacidade encontrada na língua se apresenta em interface com a amplitude da experiência humana, pelo fato de a fala direcionada à criança incluir seu contexto familiar, histórico, social e cultural.

\section{Das contribuições de Luria}

A psicologia sempre se preocupou com o papel da linguagem na comunicação entre sujeitos e também na formação da consciência, já que, diferentemente de outros animais, o homem consegue ir além da percepção do que o circunda dada a sua capacidade de abstrair. Esta característica humana ultrapassa os limites de uma experiência sensorial imediata, abrindo a possibilidade para a formação de conceitos abstratos (LURIA, 1986), os quais são desenvolvidos ao longo de nossas vidas.

Reconhecendo a importância da linguagem para além da comunicação, o autor buscou apreender a gênese da linguagem tanto no ser humano (ontogênese), quanto ao longo da história (filogênese), concluindo que, ao homem, é permitido analisar e tirar conclusões com base em seu raciocínio e não por meio de experiências imediatas e individuais. Nisso, a linguagem revela-se absolutamente fundamental, já que lhe confere 
a capacidade de pensar e concluir sobre fatos que ele não efetivamente experimentou ou viveu.

Essa habilidade de operar sobre um plano abstrato - plano que só existe pela linguagem - motiva Luria a entender a relação entre consciência e expressão linguística, ou como propõe em seu livro, entre pensamento e linguagem. Discípulo e colaborador de Vigotski, Luria (1986, p. 20-21) parte da tese desse autor de que,

[...] para explicar as formas mais complexas da vida consciente do homem, é imprescindível sair dos limites do organismo, buscar as origens desta vida consciente e do comportamento 'categorial', não nas profundezas do cérebro ou da alma, mas sim nas condições externas da vida e, em primeiro lugar, da vida social, nas formas histórico-sociais da existência do homem.

Portanto, considera a interação do sujeito com a realidade - pautada na linguagem - seu campo de pesquisa, partindo do fato de que os sujeitos se deparam com diferentes necessidades para as quais demandam certas atividades próprias para refletir as condições no mundo externo ${ }^{1}$ no organismo, elaborando informações e conhecimento.

Essa busca de respostas através da interação entre sujeito e seu entorno a fim de compreender as condições do mundo externo no interno advém de seu referencial teórico de base, a psicologia marxista, a qual considera que as origens do pensamento abstrato e do comportamento categorial necessitam ser buscadas fora do homem, isto é, nas formas sociais de sua existência histórica. Desta maneira, estabelece-se uma análise científica determinista nas chamadas formas complexas de atividade consciente do homem, investigando as origens da consciência na relação deste homem com a realidade, em sua história social (história esta absolutamente conectada com o trabalho e a linguagem), o que diferencia esta vertente da psicologia tradicional da época, para a qual as origens da consciência humana estariam na alma ou em mecanismos cerebrais.

O trabalho, considerado pelo autor como origem da necessidade de elaborar essas informações e passá-las adiante, inaugura o que Luria (1986) chamou de "pensamento abstrato categorial”, ação esta que, inicialmente, possuía um caráter "simpráxico" por estar ligado à prática, isto é, ao que podia ser visto e/ou presenciado. Aos poucos, no entanto, a linguagem tornou-se um instrumento decisivo do conhecimento humano pelo qual o homem conseguiu superar os limites da experiência sensorial (do aqui e agora) para uma individualização das características dos fenômenos, por meio da formulação de generalizações e da elaboração de conclusões, a partir de informações, e da compreensão de situações ou da função de objetos que não conhece, entre outras ações.

Com isso, o autor introduz um dos temas estudados por Vigotski: a construção de conceitos através dos processos de abstração e generalização que a linguagem nos

\footnotetext{
${ }^{1}$ Luria (1986) utiliza as pesquisas de Bernstein, Miller, Galanter, Pribam e outros sobre os sistemas biológicos elementares e a forma como eles interagem com o meio ambiente em um processo de intercâmbio de substâncias (com a absorção e assimilação das que são necessárias e excreção das substâncias que não mais colaboram com o organismo ou não podem ser aproveitadas) para fazer uma analogia com o objeto de pesquisa da psicologia como integração do mundo externo e interno. Dando continuidade à pesquisa, os autores consideram que, nos níveis fisiológicos mais complexos, a base da vida se dá na integração dessas circunstâncias externas e internas.
} 
oferece em situações enunciativas. Esta construção de conceitos com a qual nos deparamos, desde a mais tenra idade, é algo de interesse de psicólogos, pedagogos e linguistas no que tange ao processo de aquisição de linguagem.

Em consonância com tais reflexões, pode-se afirmar que é em nossas representações que está a chave para se compreender o sujeito diante de sua própria linguagem e história. A palavra consiste assim, para Luria, no elemento fundamental da linguagem, na matéria-prima de que dispõe o sujeito para construir, em sua fala, o sentido simbolicamente mediado pela cultura ${ }^{2}$.

\section{Das contribuições de Culioli}

A Teoria das Operações Enunciativas, fundada por A. Culioli, constitui-se como uma teoria da enunciação na medida em que adota como objeto de análise o próprio enunciado. O termo operação é sustentado pela premissa de que o valor referencial do enunciado não é dado, mas, sim, construído por um conjunto de operações de natureza da linguagem (FRANCKEL; PAILLARD, 2006). A enunciação diz respeito, assim, ao funcionamento da atividade de linguagem, e, ao pensar nessa dinâmica, Romero (2010) aponta a necessidade de atribuirmos à matéria semântica da palavra uma natureza relacional e abstrata, o que se conhece por "sentido", consistindo em algo não estabilizado e não acabado fora da integração da palavra em um enunciado.

$\mathrm{Na}$ perspectiva culioliana, a atividade de linguagem é permeada por três processos fundamentais, sendo eles a representação, a referenciação e a regulação.

No processo de representação, a linguagem é constitutiva de uma forma de pensamento. Ela constrói representações mentais de uma determinada natureza, que compreendemos como o sentido do que expressamos, construímos e compreendemos quando falamos, escrevemos, lemos e interpretamos. Ao pensar nessa perspectiva, atribuímos ao sentido uma natureza relacional e contextual ${ }^{3}$, como dissemos, não previamente dado. Isso mostra que a linguagem não pode ser entendida como um "instrumento, uma tradução ou um código que permitiria passar do pensamento ao verbo (supondo-se que pudéssemos saber ao certo o que é "O pensamento")" (DE VOGUÉ; FRANCKEL; PAILLARD, 2011, p. 11-12).

A esse respeito, importa dizer, ainda, que

[...] as representações mentais são organizadas a partir das experiências que elaboramos desde nossa infância mais longínqua, que construímos a partir de nossas relações com o mundo, com os objetos, com o outro, do fato de pertencermos a uma cultura, do interdiscurso no qual nos banhamos (CULIOLI, 1990, p. 21).

\footnotetext{
${ }^{2}$ Poderíamos, aqui, resgatar as contribuições de Benveniste, para quem a linguagem oferece o modelo de uma estrutura relacional, no sentido mais literal e mais compreensivo, ao vincular, "no discurso, palavras e conceitos, e produz[ir] assim, como representação de objetos e de situações, signos que são distintos dos seus referentes materiais." (BENVENISTE, 1976, p. 30).

3 Vale a pena ressaltar que, ao falarmos em uma natureza relacional e contextual, refutamos o posicionamento para o qual o contexto da enunciação seria o responsável pela significação. Não se pode dizer que esse contexto seria determinante para a "modificação" de um significado já preexistente de uma palavra ou expressão.
} 
A referenciação consiste em operações por meio das quais a linguagem permite dizer algo do mundo. Incluem os arranjos de formas derivados da materialidade das línguas constituindo-se em um modo particular de apreender este mundo. Assim, este modo de dizer aponta uma "lacuna a se preencher ou reformular, apreendida sempre entre o informulável e o formulável [...]. É uma construção, o mundo apreendido como dito do modo como é dito [...]; o mundo, quando da ordem do dizer, é, então, o lugar em que se exprime o irredutível distanciamento entre o dizer e o querer dizer, de todas as maneiras possíveis de expressão (sofrimento, falha, criatividade, recurso poético, reformulação, gaguejos" (DE VOGUÉ; FRANCKEL; PAILLARD, 2011, p. 12), dentre outros recursos.

Já a regulação evoca o jogo de relações entre posições enunciativas construídas nos e pelos enunciados. Tais posições não se configuram como oriundas de indivíduos em sua singularidade de sujeitos, mas do que os enunciados, como arranjos formais que são, permitem reconstruir em termos de sentido. Essa reconstrução, necessariamente variável que se dá na interlocução, desencadeia um processo de ajustamento que conduz a negociações e diferentes estabilizações semânticas (DE VOGUÉ; FRANCKEL; PAILLARD, 2011, p. 12). Evidenciamos, com esse processo, o modo pelo qual o dizer da criança se vê regulado pelos enunciados, o modo como (re)constrói sentidos em função do que a sua produção verbal diz do mundo e representa nos enunciados.

Salientamos, nessa perspectiva, que o sentido de toda produção verbal, seja esta mediada pela expressão oral, escrita ou gestual, deve ser buscado no próprio desenrolar do processo de enunciação, na interação entre a unidade e seu(s) contexto(s), o que faz com que os sentidos se encontrem em um permanente processo de construção e estabilização enunciativas (ROMERO, 2010). É por concordarmos com isso que tendemos a falar em "identidade semântica" das unidades linguísticas, visto a capacidade de construção de significações ocorrer ao se enunciar.

Por fim, o jogo dialético entre representação, referenciação e regulação configura o processo de construção de significação no e para o sujeito e aponta, igualmente, para uma particularidade da atividade linguística: o que a sustenta é um funcionamento dinâmico, constituído por ajustamentos intersubjetivos, por unidades dotadas intrinsecamente de variação e pela não existência de sentidos prévios à materialidade verbal. Esse jogo diz, portanto, a flexibilidade necessária à atividade enunciativa, ao mesmo tempo em que exige estabilizações oriundas do pôr em uso da língua em enunciados.

\section{Uma análise sobre os cenários enunciativos infantis}

A fim de apresentar exemplos deste jogo permanente entre os três processos citados, trazemos dois cenários enunciativos como corpus, que integram o banco de dados NALíngua (CNPq/UNESP-FCLAr), coordenado por Del Ré. As análises propostas centram-se nas interações lúdicas envolvendo contextos em que se observam, no primeiro, o questionamento da criança em busca da construção de um sentido no diálogo e, no segundo, o questionamento do interlocutor direcionado à criança sobre o que ela traz como sentido, problematizando a construção da significação. Tais cenários são ilustrados a seguir. 


\section{Cenário enunciativo 1: criança de 6 anos e 7 meses}

$\mathrm{Na}$ situação observada, há um jogo de perguntas e respostas, com cartas e ilustrações, com o qual pai e fillha brincam, sentados ao chão. O jogo envolve questões sobre diferentes temáticas (história, atualidades, conhecimentos gerais), devendo, cada participante, escolher uma temática preferida e responder perguntas sobre ela. A criança escolhe com frequência a temática da Turma da Mônica, aparentemente por se interessar pelos personagens, assim como conhecê-los com maior propriedade do que, por exemplo, a temática de conhecimentos gerais. Como se vê no diálogo abaixo, após retirar uma carta sobre o Chico Bento, o pai questiona a filha com as informações da ficha de pergunta:

Pai: Qual é o passatempo do Chico Bento?

Filha: O que seria passatempo?

Pai: Passatempo é aquilo que você gosta de fazer.

Filha: Ah! Então o passatempo do Chico Bento é comer goiaba.

Pai: Ah! Eu aceito essa resposta.

Com base na interação ilustrada acima, notamos que a construção de sentido é mediada pelo mundo das palavras e por movimentos discursivos ajustáveis entre criança e adulto. A palavra não deve ser entendida como um rótulo que traz um sentido, designa um objeto ou postula uma qualidade isolada. Na realidade, a identidade semântica da palavra é revelada no ato enunciativo e requer um enfoque muito mais amplo de seu funcionamento.

Tradicionalmente, o sentido da palavra passatempo, conforme encontramos em dicionários, pressupõe uma "ocupação agradável a que a pessoa se entrega para passar o tempo; divertimento" ". Este conhecimento que os dicionários nos trazem é de grande importância para a compreensão de palavras novas ou de outra língua que não a nossa. Sabemos, porém, que não podemos considerá-lo como um significado dado e fixo, sem a possibilidade de variação de sentido ao longo do tempo ou em diferentes situações de interação. Diferentemente de nosso entendimento sobre a significação como algo construído, modelos tradicionais que sustentam a existência de traços semânticos, ainda comumente observados nos domínios da aquisição da linguagem e da semântica lexical, repousam no princípio de que o sentido das palavras se caracteriza por meio de semas, traços semânticos ou ainda átomos de sentido.

A posição teórica adotada neste trabalho difere de tais modelos e tem seus fundamentos, de um lado, em uma perspectiva enunciativa da aquisição de linguagem, mais precisamente, na concepção construtivista da significação inspirada na Teoria das Operações Enunciativas, de outro, nas reflexões advindas do campo da psicologia, especialmente da teoria de Luria (1986).

Portanto, retomando a situação descrita, percebemos que a criança não compreendeu o conceito de "passatempo", e por isso questionou o pai, em busca de uma definição, para que então pudesse formular sua resposta. O pai, ao definir passatempo

\footnotetext{
${ }^{4}$ BECHARA, E. (Org.). Dicionário escolar da Academia Brasileira de Letras: língua portuguesa. São Paulo. Companhia Editora Nacional, 2011.
} 
como "o que você gosta de fazer" abre precedente para que a filha responda "comer goiaba", já que, nas histórias em quadrinhos da Turma da Mônica, o personagem Chico Bento aparece com frequência buscando e comendo goiabas.

Ampliando nossas reflexões, ao dizer "Eu aceito essa resposta", o pai não está simplesmente dizendo "É isso mesmo!" ou então "Você acertou!". O aceitar a resposta permite que se interprete a fala do pai como alguém que, por um momento, teve que avaliar se a aceitaria ou não, se o que foi dito pela filha poderia ser pensado como algo que define o que vem a ser "passatempo". Por fim, entendemos que o pai valida o que foi dito pela criança, pois, na interação produzida, com a definição dada por ele, a criança, por meio de processos de representação e referenciação, formulou a hipótese de que "comer goiaba" (um hábito, um gosto, mas que, em uma dada perspectiva, dificilmente seria definido como "passatempo") poderia ser chamado de "passatempo do Chico Bento".

Neste caso, percebemos que o pai foi parcialmente obrigado a aceitar a resposta, que poderia não ser a resposta correta ou, pelo menos, a esperada pelo jogo (como brincar com amigos, subir em árvores, dormir, etc.), pois foi a sua explicação ("Passatempo é aquilo que você gosta de fazer") que deu abertura para que a criança chegasse a uma conclusão que a fez pontuar no jogo.

Dizer "Eu aceito a resposta" passa, no entanto, por uma posição em que a resposta poderia, finalmente, ter sido recusada e não o foi. Neste contexto, há uma análise sobre a atividade de linguagem que nos remete à construção de sentido que o próprio pai poderia atribuir à palavra "passatempo" (e, que, de modo ou de outro, aproxima-se de uma ocupação agradável a que a pessoa se entrega). Ele só não falou que esse algo que a gente gosta de fazer faz passar o tempo.

Ressaltamos aqui a ocorrência da interligação entre os processos de representação, referenciação e regulação, de modo que as representações emergem do esforço imaginativo da criança sobre o personagem Chico Bento, o que ela sabe sobre ele e que lhe permitiu dizer algo sobre o seu passatempo, elaborando um conceito de "passatempo" na interação com a resposta dada pelo pai. O processo de regulação é mediado pela fala do pai, o qual, ao atribuir uma resposta flexível ao questionamento da criança, lhe possibilitou construir um sentido para a palavra estimulado pelo cenário da turma da Mônica. Tal aspecto fica claro ao aceitar a resposta, o que permite a emergência da estabilização de sentido, sentido este que só foi estabelecido de acordo com a definição (como dissemos, aberta) que o pai deu à sua filha.

Esses movimentos ajustáveis presentes nas falas entre pai e filha viabilizaram a construção do conceito de "passatempo", como colocaria Vigotski e Luria, ou do sentido de "passatempo" como apontaria Culioli, acontecem na interação, na enunciação. Vale destacar a relevância da conduta do pai, na medida em que ela contribuiu não só para a construção pela criança de questionamentos, como também a estimulou a adquirir, utilizar, construir e transformar os sentidos da língua, evidenciando sua essência dinâmica. Isso justifica nossa apreciação pela análise sobre a atividade de linguagem, e em refletir, simultaneamente, sobre os domínios teóricos da 
TOE $^{5}$ aplicados nos estudos sobre aquisição, em especial, quando destacamos a conduta ativa da criança na produção de uma rede de sentidos que o cenário enunciativo evoca.

Do ponto de vista psicológico, por sua vez, a palavra não se esgota em uma referência fixa e unissignificativa. Tanto o processo de denominação, quanto o de percepção da palavra na realidade deve ser, portanto, examinado como um complexo processo de escolha necessário do "significado da palavra", entre tudo o que ela evoca (LURIA, 1986).

\section{Cenário enunciativo 2: criança de 5 anos e 10 meses}

$\mathrm{Na}$ situação em que ocorre essa interação, a pesquisadora está ao lado da criança e elas olham um livro de adesivos manejado pela criança. A pesquisadora pergunta à criança sobre uma página específica, em que há um desenho de um palhaço feito com adesivos, completando a figura (trata-se de uma brincadeira de colar adesivos em uma dada figura). A criança, então, inicia o diálogo, presente em Del Ré (2003):

Criança: e esse (o palhaço do outro lado da folha) esse daqui (olha sorrindo para pesquisadora)

Pesquisadora: (sorrindo) ahn

Criança: o olho... é quebrô (ri e olha para pesquisadora)

Pesquisadora: (ri) ahn

Criança: (sorrindo) o olho machucô: (risos)

Pesquisadora: (rindo) como é que é um olho quebrado?

Criança: aqui oh (apontando para o olho do palhaço)

Pesquisadora: ahn

Como dissemos, a criança mostra uma página em que há um palhaço com adesivos completando sua figura (como partes do rosto, adereços, etc.). Porém, nesta imagem específica para a qual a criança chama a atenção do adulto, um dos adesivos que representaria o olho estava ausente/danificado.

É interessante notar, nesse exemplo, que a criança, por um lado, constrói um enunciado sabendo, pelo sorriso que dá, que faz um uso inusitado do emprego de "quebrar", já que, em nossa representação usual, um olho humano não é passível de ser quebrado. Considerando, no entanto, que o diálogo aparece em uma situação de colagem, em que se espera que os adesivos constituam a figura do palhaço, dizer que o olho quebrou pode apontar justamente para uma "partição" em relação ao todo: naquele ponto representado pelo "olho do palhaço", algo está destruído em relação à totalidade da figura do palhaço; ou, então, algo fez com que a "inteireza" representada pelo

\footnotetext{
5 Assim, para a Teoria das Operações Enunciativas, a existência de traços semânticos, bem como a normatividade atribuída ao funcionamento da língua, é questionável. Isso implica dizer que, na interação dialógica, toda construção de sentido ocorre por meio de processos de ajustamentos intersubjetivos, modulações e jogos contextuais entre os (co)enunciadores. É por isso que não podemos afirmar o sentido de "passatempo", mas construí-lo a cada enunciado e, se assim desejarmos, analisar as possibilidades de construção para então compreender sua identidade semântica, isto é, o que lhe é próprio do ponto de vista de sua matéria semântica que lhe permite ser enunciado em alguns contextos específicos, contextos que não são quaisquer.
} 
palhaço não fosse plenamente apreciada pela criança: no olho, há uma falha ou um defeito (ROMERO, 2010).

A pesquisadora não valida o enunciado como "Poxa, realmente o olho quebrou!", ela apenas diz "ahn..." rindo. Sua atitude, no entanto, parece ser suficiente para que a criança, antes mesmo de ser questionada sobre como um olho poderia quebrar, traga em sua fala, na sequência, um movimento ajustável, reformulando o enunciado: "o olho machuco". Em outras palavras, neste enunciado, a criança parece ajustar a sua fala anterior, referente ao olho quebrado, apresentando a partir da reação do adulto, no enunciado reformulado, o olho como parte do corpo humano que se machucou, na tentativa de também se fazer entender.

Aproveitando esse momento de reformulação, a pesquisadora questiona a criança sobre como seria então um olho quebrado, e, aparentemente mais segura com sua conclusão de que quebrado também aproxima-se de machucado, uma parte em relação ao todo do desenho do palhaço, ela mostra novamente a imagem.

O ponto central de nossa análise é, novamente, observar esse movimento ajustável conduzido pela criança em interação com seu interlocutor, em especial, quando se utiliza de seus próprios recursos linguísticos para estabilizar o sentido de uma palavra. Um dos recursos utilizados, e que observamos nos dois cenários, é o contexto lúdico que parece estimular as duas crianças a utilizar elementos de sua imaginação, denotando a sua capacidade de apreender a dinamicidade ligada não só ao processo de aquisição da língua materna, mas também ao seu funcionamento.

O jogo de relações entre as posições enunciativas construídas no enunciado conduziu as reflexões estimuladas pela TOE sobre a atividade de linguagem, destacando os elementos dinâmicos e maleáveis estabelecidos na interação contextual que compõem a construção de sentido e caracterizam o funcionamento da língua.

Assim, os exemplos ilustrados acima dão pistas da compreensão apresentada pelas crianças quanto à delimitação do uso da língua e do sentido construído em cada interação. Observamos ainda que os contextos de questionamentos e respostas, tanto da criança ao interlocutor, quanto do interlocutor à criança, revelaram-se como elementos linguísticos importantes e motivadores, estimulando a produção verbal, bem como a estabilização do sentido de algumas palavras naqueles contextos específicos. A partir de um jogo contextual, a criança se apresenta capaz de construir um sentido relacional de palavras e expressões e sinaliza seus primeiros passos criativos na língua e no movimento ajustável que caracteriza o seu funcionamento.

\section{Considerações finais}

Percebemos, nos enunciados infantis, a presença de movimentos ajustáveis em que se veem elementos da imaginação da criança em diálogo com o seu meio e com todas as reconfigurações linguísticas possíveis. Neste contexto, as crianças apresentamse como sujeitos ativos, no processo de aquisição e na produção enunciativa.

Por meio do contexto de questionamentos, as crianças não só se expressaram com seus recursos linguísticos, como os transpuseram para cenários enunciativos, atribuindo-lhes novos sentidos em cada produção verbal, sendo os aspectos relacional e 
contextual, certamente, recursos fundamentais a serem analisados na construção de sentido viabilizada pela língua(gem).

A partir do aporte da Teoria das Operações Enunciativas, foi possível analisar a atividade da linguagem infantil, observando, nos cenários enunciativos 1 e 2 , como as crianças construíram esferas mentais representativas de uma determinada natureza produzindo sentido, como os arranjos derivados da materialidade da língua foram utilizados por elas para dizer algo sobre os questionamentos.

Nessa perspectiva, enfatizamos a importância da abertura da ciência psicológica a diálogos com ciências como a linguística, promovendo a possibilidade de apropriação de análises sobre o funcionamento da linguagem que, a nosso ver, podem colaborar para a construção de uma rede de sentido flexível que liberte a língua de atribuições estáticas, perspectiva essa que não é coerente com a vivacidade da atividade linguística e das possibilidades que a língua tem de se alterar ao longo do tempo.

\section{REFERÊNCIAS}

ALMEIDA, S. R. de. O brincar e seus tons: reflexos do lúdico no processo de aquisição da linguagem. 2015. 128 f. Dissertação (Mestrado em Educação e Saúde na Infância e na Adolescência) - Universidade Federal de São Paulo, Escola de Filosofia, Letras e Ciências Humanas, Guarulhos, 2015.

BECHARA, E. (Org.). Dicionário escolar da Academia Brasileira de Letras. São Paulo: Companhia Editora Nacional, 2011.

BENVENISTE, E. Vista d' olhos sobre o desenvolvimento da linguística. In: Problemas de linguística geral. Tradução de Maria da Glória Novak e Maria Luísa Neri, revisão de Isaac Nicolau Salum. São Paulo: Ed da Universidade de São Paulo, 1976.

BEZERRA, P. Prólogo do Tradutor. In: VIGOTSKI, L. S. A Construção do Pensamento e da Linguagem. 2. ed. São Paulo: Martins Fontes, 2010. p. VII-XIV.

CULIOLI, A. Pour une linguistique de l'énonciation: formalisation et opérations de repérage. Paris: Ophrys, 1990.

CULIOLI, A.; NORMAND, C. Onze rencontres sur le langage et les langues. Paris: Ophrys, 2005.

DE VOGUÉ, S.; FRANCKEL, J. J.; PAILLARD, D. Prefácio. In: DE VOGUÉ, S. et al. Linguagem e enunciação: representação, referenciação e regulação. São Paulo: Contexto, 2011.

DEL RÉ, A. A criança e a magia da linguagem: um estudo sobre o discurso humorístico. 2003. 264 f. Tese (Doutorado em Linguística) - Faculdade de Filosofia, Letras e Ciências Humanas, Universidade de São Paulo, São Paulo, 2003.

FRANCKEL, J. J.; PAILLARD, D. Aspectos da Teoria de Antoine Culioli. Tradução de Daniel Costa da Silva. Organon: Porto Alegre, 2006. Disponível em: <seer.ufrgs.br>. Acesso em: 09 jul. 2016.

LURIA, A. R. Pensamento e linguagem: as últimas conferências de Luria. Artmed, 1986. 
ROMERO, M. Um possível diálogo entre a teoria das operações enunciativas e a aquisição: identidade semântica e produtividade discursiva. Alfa, São Paulo, v. 54, n. 2, p. 475-503, 2010.

Epilinguismo: considerações acerca de sua conceitualização em Antoine Culioli e Carlos Franchi. ReVEL, v. 9, n. 16, p. 152-163, 2011.

VYGOTSKY, L. S. A Construção do Pensamento e da Linguagem. 2. ed. São Paulo: Martins Fontes, 2010.

YAGUELLO, M. Ah, dedica-se à linguística! In: YAGUELLO, M. Alice no país da linguagem: para compreender a linguística. Lisboa: Editorial Estampa, 1991.

Recebido em: 15/08/2016

Aprovado em: 10/02/2017 